\title{
Vankomisine dirençli enterokokların saptanmasında iki farklı kromojenik besiyerinin karşılaştırılması
}

\section{Comparison of two different chromogenic agar for isolation of vancomycin-resistant enterococci}

\author{
Sami KINIKLI* Salih CESUR@, Çiğdem ATAMAN HATIPOĞLU@, Kader ARSLAN@, Taliha KARAKÖK@, \\ Şerife ALTIN DEMIRCAN@ Esra KAYA KILIÇ@, Ayşe BÜYÜKDEMIIRCi]
}

Ankara Eğitim ve Araştırma Hastanesi, Enfeksiyon Hastalıkları ve Klinik Mikrobiyoloji Kliniği, Ankara/TÜRKIYE

\section{Öz}

Amaç: Bu çalışmada yoğun bakım ünitesinde yatan hastaların rektal sürüntü örneklerinden vankomisin dirençli enterokokların saptanmasında Enterococcosel agar ve ChromID VRE besiyerinin performanslarının karşılaştııılması amaçlandı.

Gereç ve Yöntemler: Yoğun Bakım ünitesinde yatan hastalardan aktif vankomisine dirençli enterokok (VRE) sürveyansı kapsamında alınan rektal sürüntü örnekleri eş zamanlı olarak Enterococosel agar ve Chrom ID VRE agar besiyerlerine ekildikten sonra besiyerleri $37^{\circ} \mathrm{C}$ 'de etüvde 24-48 saat süreyle inkübe edildi. Enterococosel agar besiyerinde siyah renkte üreyen koloniler olası VRE olarak değerlendirilmeye alındı, bu suşlar kanlı agar besiyerine pasajlandı. Chrom ID VRE agar besiyerinde menekşe rengi üreyen koloniler olası vankomisine dirençli Enterococcus faecium, yeşil renkte üreyen koloniler ise olası Enterococcus faecalis suşları olarak değerlendirmeye alındı. Her iki kromojenik besiyerinde üreyen olası VRE suşlarının doğrulanması E-test yöntemiyle ve otomatize antibiyotik duyarlılık sitemiyle MiK değeri belirlenerek saptandı. Besiyerlerinin duyarlılık, özgüllük, pozitif belirleyicilik değeri (PBD) ve negatif belirleyicilik değeri (NBD)'leri; vankomisin E-test yöntemi ve otomatize antimikrobiyal duyarlılık yöntemiyle saptanan değerler göz önüne alınarak hesaplandı.Vankomisin direncini saptamakta E-test yöntemi ve otomatize sistem birbiriyle \%100 uyumluydu.

Bulgular: Çalışmaya yoğun bakım ünitesinde yatan hastalardan alınan 159 rektal sürüntü örneği dahil edildi. Rektal sürüntü örneklerinden E-test yöntemiyle ve otomatize antimikrobiyal duyarlıık test yöntemiyle doğrulanmış 21 (\%13) VRE saptanırken, 138 (\%87) örnekte VRE saptanmadı. Enterocosel agar besiyerinin 24 ve 48. saatlerdeki duyarlııı, özgüllük, PBD ve NBD'leri sırasıyla; \%95.4, \%99.2, \%99.2 ve \%98.7 idi. Chrom ID VRE agar besiyerinin 24 ve 48. saatlerdeki duyarlılık, özgüllük, PBD ve NBD'leri sırasıyla; \%95.4, \%81.7, \%45.6 ve \%99.1 idi. Her iki besiyerininin de 24 . ve 48. saatlerdeki duyarlılık ve özgüllük oranları farklılık göstermedi. Enterococcosel agar besiyerinin duyarlılığı ve PBD'i ChromID VRE agar besiyerinden daha yüksekti. Chrom ID VRE agar besiyerinde yalancı pozitiflik oranının $(25 / 159, \% 16)$ daha fazla olduğu olduğu saptandı. Enterococosel agar besiyerinde yalancı pozitiflik oranı \% $0.6(1 / 159)$ idi.

Sonuç: Rektal sürüntü örneklerinde VRE suşlarının saptanmasında Enterococosel agar besiyerinin özgüllük oranının Chrom ID VRE agar besiyerinden daha iyi olduğu saptandı. Ayrıca, Chrom ID VRE agar besiyerinde Gram negatif bakterilere bağlı yalancı pozitifliklerin fazla olması nedeniyle bu besiyerine Gram negatif etkinlikli antibiyotik eklenmesinin yararlı olacağı sonucuna varıldı.

Anahtar kelimeler: vankomisine dirençli enterokok; kromojenik besiyeri; enterococcosel agar; chrom ID VRE agar

Sorumlu Yazar*: Sami Kınıklı, Ankara Eğitim ve Araştırma Hastanesi, Enfeksiyon Hastalıkları ve Klinik Mikrobiyoloji Kliniği, Ankara/TÜRKiYE E-posta: dr_sami_kinikli@hotmail.com

ORCID: 0000-0001-5169-9702

Gönderim: 23.09.2017 Kabul: 03.11.2017

Doi: $10.18663 /$ tjcl.339592 


\section{Abstract}

Aim: The aim of this study is to compare performances of Enterecoccosel Agar and ChromIDVRE on detecting vancomycinresistant enterococci from rectal swab specimens of the patients in intensive care unit.

Material and Methods: Rectal swab specimens taken from the patients in intensive care unit were simultaneously plated in both Enterococosel agar and ChromID VRE agar, and then, they were incubated in incubator at $37^{\circ} \mathrm{C}$ for $24-48$ hours. Black colonies on Enterococcosel agar were identified as possible VRE. Purple and pink colonies on ChromID VRE agar were identified as possible vancomycin resistant Enterococcus faecium. Green colonies on ChromID VRE agar were identified as possible vancomycin resistant Enterococcus faecalis. Vancomycin resistance were confirmed by vancomycin E-test and automated antimicrobial susceptibility test through the MIC values. The sensitivity, specificity, positive predictive value (PBD) and negative predictive value (NBD) of the agars were calculated by taking into account the values determined by the vancomycin E-test method and the automated antimicrobial susceptibility method. In detecting vancomycin resistance, the E-test method and the automated antimicrobial susceptibility method were found to be $100 \%$ compatible.

Results: For the study, 159 rectal swabs taken from patients in intensive care unit were analyzed. 21 (13\%) VRE, which are confirmed by E-test and automated antimicrobial susceptibility test, were detected in rectal swab specimens, but VRE was not detected in $138(87 \%)$ specimens. Sensitivity, specificity, PBD and NBD of enterococcal agar at 24 and 48 hours were; 95.4\%, 99.2\%, 99.2\% and 98.7\%, respectively. Sensitivity, specificity, PBD and NBD of Chrom ID VRE agar at 24 and 48 hours were; $95.4 \%, 81.7 \%, 45.6 \%$ and $99.1 \%$, respectively. Sensitivity and specificity rates at 24 th and 48 th hours of both agars did not differ. Sensitivity and PBD of Enterococcocel agar were higher than ChromID VRE agar. It was found that the false positive rate $(25 / 159,16 \%)$ was greater in Chrom ID VRE agar. The false positive rate on Enterococosel agar was $0.6 \%(1 / 159)$.

Conclusion : In conclusion, this study revealed that the specifity rate of Enterococcosel agar in detecting VRE from rectal swabs was higher than ChromID agar. However, it is recommended that an antibiotic for gram negative bacteria should be included in ChromID agar in order to prevent false positive results.

Keywords: vancomycin-resistant enterococcus; chromogenic media; enterococcosel agar; chrom ID VRE agar

\section{Giriş}

Enterokoklar gastrointestinal florada yer alan önemli bir hastane kaynaklı infeksiyon etkenidir. Son zamanlarda vankomisine dirençli enterokok (VRE)'lar yoğun bakım ünitesinde hastane kaynaklı infeksiyonlara ve salgınlara neden olmaktadır [1]. VRE suşları çoğu antibiyotik grubuna dirençlidir ve vankomisin direncini oldukça virülan olan metisiline dirençli Staphylococcus aureus suşlarına aktarabilir.VRE bağlı olarak gelişen nozokomiyal infeksiyonların morbidite ve mortalite oranları yüksektir. Ayrıca, hastalarda tedavi seçenekleri kısıtlı olduğundan hasta bakım maliyetlerinde artışa da neden olur [2].

Vankomisine dirençli enterokoklara bağlı salgınları ve infeksiyonları önlemek için VRE ile infekte veya kolonize olan hastaların erkenden saptanıp,sıkı temas izolasyon önlemlerinin uygulanması gerekir [1,3]. Bu amaçla, riskli ünitelerde (yoğun bakım ünitesi, hematoloji-onkoloji servisi, yenidoğan ünitesi vb.) yatan hastalarda VRE kolonizasyonunun seçici veya ayırd edici besiyerleri ile rektal sürüntü veya dışkı örneklerinde taranarakaktifsurveyansının yapılması önerilmektedir[1,2,4-6].
Bu amaçla, kromojenik substratların kullanıldığı, duyarlılık oranı yüksek selektif kromojenik besiyerleri geliştirilmiştir. $\mathrm{Bu}$ besiyerleri VRE suşlarının erken tanımlanmasına ve etkili infeksiyon kontrol önlemlerinin alınarak nozokomiyal bulaşın engelenmesine imkan sağlar .Bu amaçla geliştirilmiş çeşitli besiyerleri mevcuttur. Bu besiyerlerinden bazıları; Enteroccoccosel agar, Chrom ID VRE agar ve Brilliance VRE agar besiyeridir [7-9].

$\mathrm{Bu}$ çalışmanın amacl, yoğun bakım ünitesinde yatan hastaların rektal sürüntü örneklerinden vankomisin dirençli enterokokların saptanmasında Enterococcosel agar ve ChromID VRE besiyerinin duyarlılık, özgüllük, pozitif belirleyici değer ve negatif belirleyici değerlerinin birbirleriyle karşılaştırılması idi.

\section{Gereç ve Yöntemler}

Çalışmaya Ankara Eğitim ve Araştırma Hastanesi Anestezi, Beyin Cerrahisi ve Kalp Damar Cerrahisi ünitelerinde yatan hastalar dahil edildi. Hastalardan rutin VRE surveyansı kapsamında alınan toplam 159 rektal sürüntü örneği aynı 
anda vankomisin ve seftazidim içeren Enterococcosel agar (Becton dickinson, USA) ve $8 \mathrm{mg} / \mathrm{L}$ vankomisin içeren ChromID VRE agar (Biomerioux,France) besiyerine ekilerek $37{ }^{\circ} \mathrm{C}$ de $24-48$ saat süreyle inkübe edildi ve besiyerleri 24 . ve 48.saatlerde üreme yönünden kontrol edildi. Enterococosel agar besiyerinde siyah renkte üreyen koloniler olası VRE olarak değerlendirilmeye alındı.

Resim 1'de enterococcosel agar besiyerinde üreyen olası VRE kolonilerinin siyah renkte görünmektedir. Bu suşlardan tek koloni alınarak koyun kanlı agar besiyerine pasajlandı. Üreyen kolonilerden katalaz testi, eskülin hidrolizi, \%6.5 NaCl'de üreme testleri yapıldı. Katalaz testi negatif, eskülüni hidrolize eden, \%6.5 NaCl'de üreyen kolonilerden Mueller Hinton agar besiyerinde E-test yöntemiyle (Biomerioux,France) ve BD Phoenix otomatize mikrobiyolojik tanımlama ve antimikrobiyal duyarlılık sistemi (Becton-Dickinson,USA) kullanılarak vankomisin için minimum inhibitör konsantrasyon (MiK) değeri belirlendi. E-test yöntemi için, 0.5 Mc Farland ayarlanan bakteri süspansiyonu steril eküvyonla Mueller- Hinton agar besiyerine yayıldı. E-test stribi içten MiK değerleri okunacak şekilde yerleştirildi. Besiyeri etüvde $37{ }^{\circ} \mathrm{C}$ de 24 saat süreyle inkübe edildi. Vankomisin için üremenin olmadığı elipsin striple keşistiği en alt kısım MiK değeri olarak belirlendi.

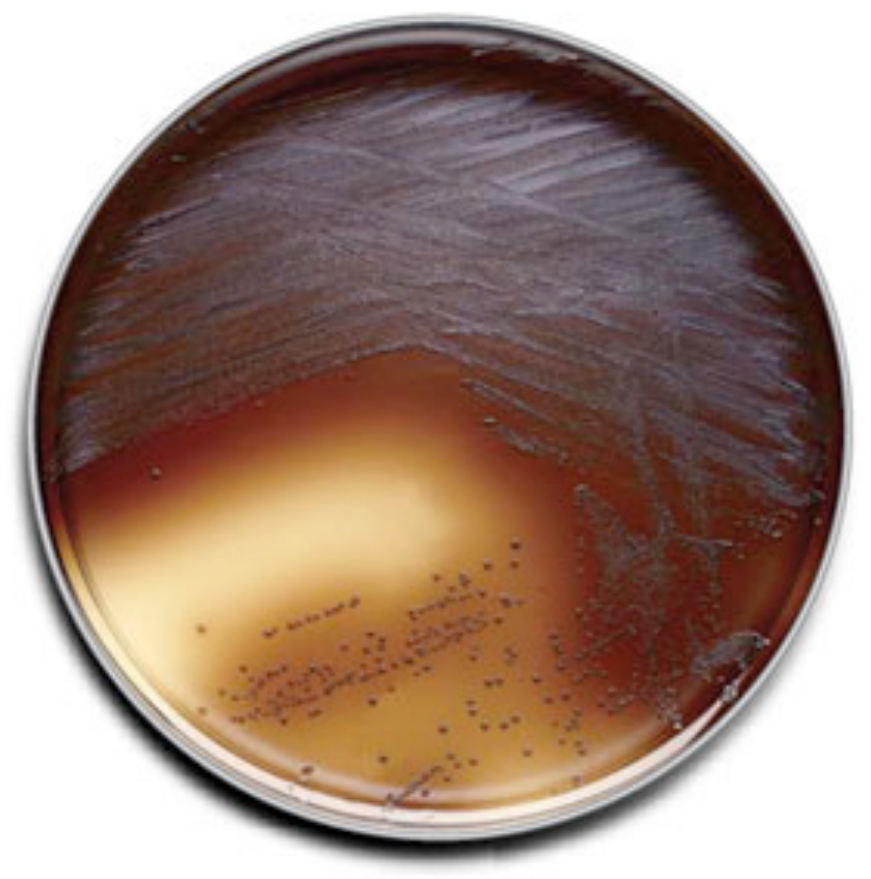

Resim 1. Enterococcosel agar besiyerinde üreyen olası VRE kolonilerinin siyah renkte görünümü

Chrom ID VRE agar besiyerinde menekşe rengi üreyen koloniler olası vankomisine dirençli Enterococcus faecium, yeşil renkte üreyen koloniler ise olası Enterococcus faecalis suşları olarak değerlendirmeye alındı. Resim 2'de chrom ID VRE agar besiyerinde üreyen olası vankomisine dirençli Enterococcus faecium kolonilerinin menekșe renkte görünümü görünmektedir. Benzer şekilde suşların VRE yönünden doğrulanması vankomisin için E-test yöntemi ve otomatize antimikrobiyal duyarlılık sistemiyle MiK değeri belirlenerek saptandı. Her iki kromojenik besiyerinin duyarlılık, özgüllük, PBD ve NBD'leri, E-test yöntemi ve $B D$ Phoenix otomatize antimikrobiyal duyarlılık sistemi referans alınarak hesaplandı.

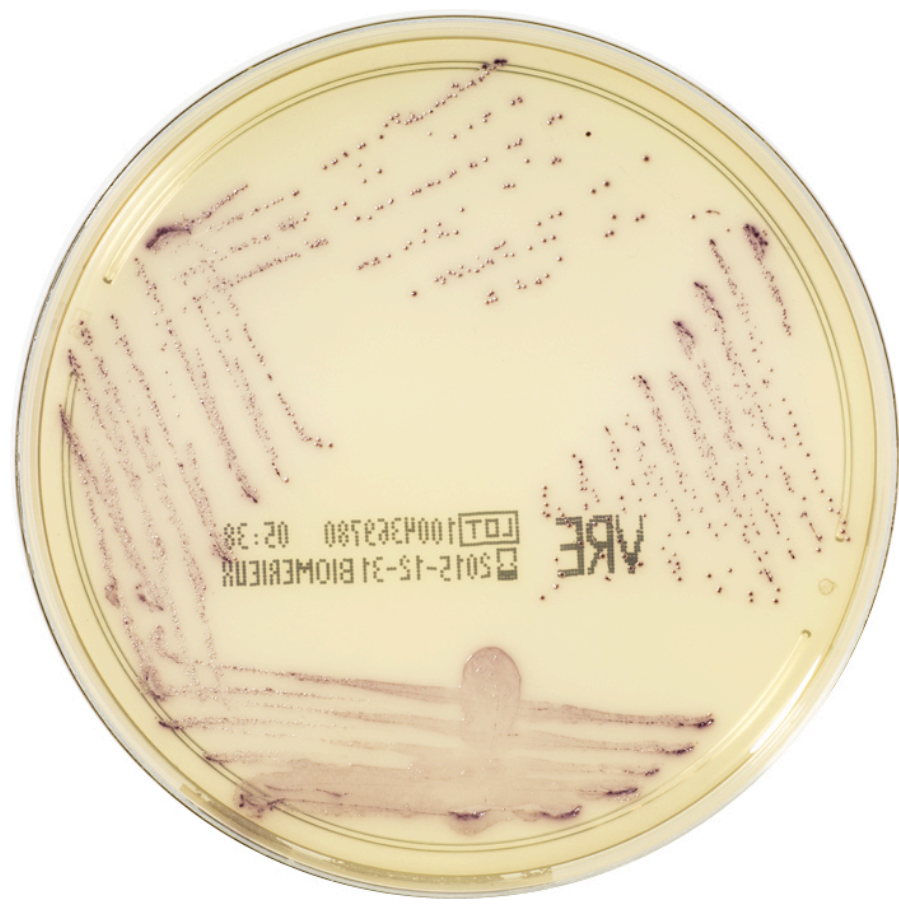

Resim 2. Chrom ID VRE agar besiyerinde üreyen olası vankomisine dirençli Enterococcus faecium kolonilerinin menekşe renkte görünümü

\section{Bulgular}

Toplam 159 dışkı sürüntü örneğinden, E-test yöntemiyle doğrulanmış 21 (\%13.2) VRE izole edildi. İzole edilen VRE suşlarının tamamı Enterocooccus faecium idi. Kromojenik besiyerlerinin duyarlılık, özgüllük, $\mathrm{PBD}$ ve NBD'leri E-test ve BD Phoenix otomatize sistemiyle belirlenen MiK değerleri esas alınarak hesaplandı. Vankomisin direncini belirlemekte E-test yöntemi ve BD Phoenix otomatize sistemi birbiriyle \%100 uyumlu idi.

Her iki besiyerinde de 24. İle 48. saatler arasındaki duyarlılık, özgüllük ,PBD ve NBD'ler değişmezken, inkübasyon süresi uzadığında özellikle ChromID VRE besiyerinde yalancı pozitif saptanan kolonilerinin sayısının arttığı saptandı.

Tablo 1'de her iki besiyerinin 24 ve 48. saatlerde VRE saptama oranları, duyarlılık, özgüllük, PBD ve NBD’leri gösterildi. 


\begin{tabular}{|c|c|c|c|c|c|c|c|c|}
\hline Besiyeri & Gerçek pozitif & Yalancı Pozitif & Gerçek negatif & Yalancı negatif & Duyarlıık (\%) & Özgüllük (\%) & PBD* (\%) & NBD** (\%) \\
\hline & 21 & 1 & 136 & 1 & 95.4 & 99.2 & 99.2 & 98.7 \\
\hline $\begin{array}{l}\text { Chrom ID VRE } \\
\text { Agar }\end{array}$ & 21 & 25 & 112 & 1 & 95.4 & 81.7 & 45.6 & 99.1 \\
\hline
\end{tabular}

Enterococcosel agar besiyerinin duyarlılığı ve PBD'i ChromID VRE agar besiyerinden daha yüksekti. Chrom ID VRE agar besiyerinde Gram negatif bakterilere (E.coli, Klebsiella spp ve Pseudomonas aeruginosa vb.) ve daha az oranda Staphylococcus aureus'a bağlı yalancı pozitifliklerin olduğu gözlendi.

\section{Tartışma}

Vankomisine dirençli enterokok suşları ile infekte veya kolonize olan hastaların erken tanısı bu bakteriye bağı olarak gelişebilecek nozokomiyal infeksiyonların önlenmesi ve infeksiyon kontrol önlemlerinin alınması için gereklidir [2]. Günümüzde VRE suşlarının saptanmasında kromojenik besiyerleri gibi selektif kültür yöntemleri ve /veya kültürle birlikte vankomisin direncinden sorumlu genlerin (van $A$, van $B$, van $C$ ) moleküler yöntemlerle (polimeraz zincir reaksiyonu (PZR), real-time PZR vb.) saptanması sıklıkla kullanılmaktadır [2,3]

Kromojenik besiyerleri hem aranan coklu direncli patojenin secilmesini sağlayan hem de icerdikleri diğer ayraclar sayesinde farklı koloni renkleri oluşturarak tür ayırımına olanak veren besiyerleridir. Bu besiyerlerinde kromojenik enzimatik substratlar ve çeşitli antimikrobiyal ajanlar bulunur [7-9] . VRE'ları saptamakta Chrom ID VRE agar, Enterococcosel agar, Brilliance VRE agar, Chromagar VRE gibi çeşitli kromojenik besiyerleri kullanılabilir. Chrom ID VRE agar besiyeri klinik örneklerde farklı renk oluşumuna neden olduğundan vankomisine dirençli Enterococcus faecium ve Enterococcus feacalis ayrımına olanak sağlar. Bu besiyerinde vankomisine direncli Enterococcus faecalis kolonileri maviyeşil, Enterococcus faecium kolonileri ise menekşe rengi görülür $[1,7,8]$. Kuch ve ark.[8] 96 iyi tanımlanmış vankomisine duyarlı ve dirençli enterokok izolatında ve 30 dışkı örneğinde (15 VRE hastası, 15 sağlıklı kişiden alınan) ChromID VRE agar ile vankomisin içeren bile eskülin agar (BEV) besiyerini karşılaştırmışlardır. Çalışmada suşlar Rapid ID32 strep test ve konvansiyonel yöntemlerle tanımlanmış, suşların vankomisin MiK değerleri E-test yöntemiyle belirlenmiştir. Çalışmada dışkı örneklerinde her iki besiyerinde VRE saptama duyarlıığı 48 saat inkübasyondan sonra anlamlı oranda değişmezken, zenginleştirilmiş besiyerine ekim sonrasında kromojen besiyerlerinin duyarlılık oranının belirgin arttığı saptanmıştır. Çalışmada ChromID VRE agarın direk kültür örneklerinde spesifitesi BEV besiyerine göre daha yüksek saptanmıştır (sırasıyla; \%100 ve \%60), ancak inkübasyon süresi 24 saatten fazla uzatıldığında özellikle Gram negatif bakteri ve Candida türlerine bağlı kontaminasyon sonucu yanlış pozitif sonuçların arttığı gözlenmiştir. Sunduğumuz çalışmada rektal sürüntü örneklerinde 24.saatten sonraki inkübasyonda (48. saatteki inkübasyonda) ChromID VRE agar besiyerinde Gram negatif bakterilere bağı üreme sonucunda yanlış pozitiflik oranlarının arttığı (159 örneğin 25'inde) saptandı. Kuch ve ark. [8] çalışmasında dışkı örneklerinde Chrom ID VRE agar besiyerinin 24. saatteki duyarlığı \%80, özgüllüğü \%100, PBD (\%100 ), NBD (\%98) olarak saptanmışken, BEV'nin duyarlığı \%100; özgüllüğü \%46, PBD \%17, \%100 olarak bildirmişlerdir. Bu çalışmada Chrom ID VRE besiyerinin 48.saatteki duyarlılığı \%93.3, özgüllüğü \%60, PBD \%21, NBD \%99 iken aynı değerler BEV için sırasıya; $\% 86.6, \% 40, \% 16$ ve $\% 96$ olarak belirlenmiştir.

Sunduğumuz çalışmada 159 rektal sürüntü örneğinde E-test yöntemiyle doğrulanmış 21'inde (\%13) VRE saptanırken, 138 (\%87) örnekte VRE saptanmadı. Enterocosel agar besiyerinin 24 ve 48. saatlerdeki duyarlılık, özgüllük, $\mathrm{PBD}$ ve $\mathrm{NBD}$ 'leri sırasıyla; \%95.4, \%99.2, \%99.2 ve \%98.7 idi. Chrom ID VRE agar besiyerinin 24 ve 48. saatlerdeki duyarlılık, özgüllük, PBD ve NBD'leri sırasıyla; \%95.4, \%81.7, \%45.6 ve \%99.1 idi. Enterococcosel agar besiyerinin duyarlılığı ve PBD'i ChromID VRE agar besiyerinden daha yüksekti.

ChromID VRE besiyerinin, vankomisin iceren safra eskulin azid (BEAV) ile kıyaslandığı bir calışmada, 24 saatlik inkübasyon sonrasında duyarlılığı \% 96.4, özgüllüğü \% 96.6, pozitif belirleyici değeri \% 89.8 olarak bildirilmiştir [10].Çalışmamızda elde ettiğimiz duyarlılık oranı bu çalışma ile benzerken, özgöllük ve PBD oranımız daha düşük saptanmıştır.

Suwantarat ve ark. [7 ] 396 dışkı örneğinde enterococosel agar ve Chrom ID VRE agar besiyerinin performansını değerlendirdikleriçalışmada, enterocococosel agarbesiyerinin duyarlılık , özgüllük, PPD ve NPD'lerini sırasıyla; 84.8, 100, 100 
ve 95.2 olarak saptanırken, Chrom ID VRE agarın aynı değerleri sırasıyla; 94.9, 99.7, 98.9 ve 98.3 olarak belirlenmiştir.

Sunduğumuz çalışmada, bu çalışmanın aksine enterococcosel agar besiyerinin özgüllük ve PPD'nin ChromID VRE agardan daha iyi olduğu belirlendi.

Çalışmamızın sınırlandırıcı yönü, VRE suşlarının maliyetinin yüksek olması nedeniyle moleküler yöntemlerle (PZR, hibridizasyon yöntemi vb.) doğrulanamaması idi.

Kromojenik besiyerlerinde yalancı pozitiflik saptanabilmesi nedeniyle pozitif saptanan suşların başka bir yöntemle (E-test, otomatize antimikrobiyal duyarlılık sistemi veya moleküler yöntemler vb.) doğrulanması gereksiz izolasyon önlemleri alınmasını engelleyecektir.

\section{Sonuç}

Chrom ID VRE agar besiyerinde Gram negatif bakterilere bağlı üreme sonucunda yalancı pozitiflik oranının fazla olması nedeniyle bu besiyerine Gram negatif etkinlikli antibiyotik eklenmesinin yararlı olabileceği görüşündeyiz.

\section{Çıkar çatışması / finansal destek beyanı}

Bu yazıdaki hiçbir yazarın herhangi bir çıkar çatışması yoktur. Yazının herhangi bir finansal desteği yoktur.

\section{Kaynaklar}

1. Cuzon G, Naas T, Fortineau N and Nordmann P. Novel Chromogenic Medium for Detection of Vancomycin-Resistant Enterococcus faecium and Enterococcus faecalis. Journal of Clinical Microbiology 2008; 46: 2442-44.

2. Seo JY, Kim PW, Lee JH, Song JH, Peck KR, Chung DR et al. Evaluation of PCR-based screening for vancomycin-resistant enterococci compared with a chromogenic agar-based culture method. J Med Microbiol 2011; 60: 945-49.

3. Zabicka D, Strzelecki J, Wozniak A, Strzelecki P, Sadowy E, Kuch A et al. Efficiency of the Cepheid Xpert vanA/vanB assay for screening of colonization with vancomycin-resistant enterococci during hospital outbreak. Antonie Van Leeuwenhoek 2012; 101: 671-75.
4. Emaneini M, Hosseinkhani F, Jabalameli F, Nasiri MJ, Dadashi $M$, Pouriran $R$ et al.Prevalence of vancomycin-resistant enterococcus in Iran: a systematic review and meta-analysis. Eur J Clin Microbiol Infect Dis 2016; 35: 1387-92.

5. Almyroudis NG, Osawa R, Samonis G, Wetzler M, Wang ES, McCarthy PL et al. Discontinuation of systematic surveillance and contact precautions for vancomycin-resistant enterococcus (VRE) and its impact on the incidence of VRE. faecium bacteremia in patients with hematologic malignancies. Infect Control Hosp Epidemiol 2016; 37: 398-403.

6. Cekin Y, Erman Daloğlu A, Oğünç D, Ozhak Baysan B, Dağlar D, Inan $D$ et al. Evaluation of vancomycin resistance 3 multiplexed PCR assay for detection of vancomycin-resistant enterococci from rectal swabs. Ann Lab Med 2013; 33: 326-30.

7. Suwantarat N, Roberts A, Prestridge J, Seeley R, Speser S, Harmon $C$ et al. Comparison of Five Chromogenic Media for Recovery of Vancomycin-Resistant Enterococci from Fecal Samples. Journal of Clinical Microbiology 2014; 52: 4039-42.

8. Kuch A, Stefaniuk E, Ozorowski T, Hryniewicz W. New selective and differential chromogenic agar medium, chromID VRE, for screening vancomycin-resistant Enterococcus species. J Microbiol Methods 2009; 77: 124-26.

9. Gülay Z. Çoklu dirençli hastane infeksiyonu etkenlerinin kontrolünde hızlı tanı testleri. ANKEM Derg 2009; 23: 193-200

10. Ledeboer NA, Das K, Eveland M et al: Evaluation of a novel chromogenic agar medium for isolation and differantiation of vancomycin resistant Enterococcus, J Clin Microbiol 2007; 45: 556-60. 